\title{
The endless tale of non-homologous end-joining
}

\author{
Eric Weterings ${ }^{1}$, David J Chen ${ }^{1}$ \\ ${ }^{1}$ Department of Radiation Oncology, Division of Molecular Radiation Biology, University of Texas Southwestern Medical Center, \\ 2201 Inwood Road, Dallas, TX 75390-9187, USA
}

DNA double-strand breaks (DSBs) are introduced in cells by ionizing radiation and reactive oxygen species. In addition, they are commonly generated during $V(D) J$ recombination, an essential aspect of the developing immune system. Failure to effectively repair these DSBs can result in chromosome breakage, cell death, onset of cancer, and defects in the immune system of higher vertebrates. Fortunately, all mammalian cells possess two enzymatic pathways that mediate the repair of DSBs: homologous recombination and non-homologous end-joining (NHEJ). The NHEJ process utilizes enzymes that capture both ends of the broken DNA molecule, bring them together in a synaptic DNA-protein complex, and finally repair the DNA break. In this review, all the known enzymes that play a role in the NHEJ process are discussed and a working model for the co-operation of these enzymes during DSB repair is presented.

Keywords: DNA-PK, Ku70/80, XRCC4, Ligase IV, Artemis, XLF, Cernunnos, DSB, NHEJ, ATM, non-homologous end-joining, DNA double-strand break, V(D)J recombination

Cell Research (2008) 18:114-124. doi: 10.1038/cr.2008.3; published online 1 January 2008

\section{The cell's response to DNA double-strand breaks}

DNA double-strand breaks (DSBs) can be introduced by any agent that is capable of severing the DNA backbone. Such agents include endogenous factors like metabolic products and reactive oxygen species, and also exogenous factors like ionizing radiation. The induction of DSBs by ionizing radiation is of particular importance, since cells are continuously exposed to background radiation. The integrity of the DNA backbone is therefore under constant attack from both the inside and the outside of the cell. When both strands of the DNA backbone are severed at closely opposed positions, the DNA molecule will literally break apart. This leads to chromosome breakage, which, in turn, presents a major challenge for cell division. During division, chromosome fragments can be distributed unequally over daughter cells or they can be translocated to places in the genome where they do not belong. In many cases, cells that are the victim of such an attack suffer death. But in the worst-case scenario, deletion or translocation of chromosome fragments leads to inactivation of tumour supressor genes or activation of oncogenes. Both events can trigger the onset of carcinogenesis in surviving cells $[1,2]$.

Correspondence: David J Chen

Tel: +1-214-648-5597; Fax: +1-214-648-5995

E-mail: david.chen@utsouthwestern.edu
In view of the serious consequences that an unrepaired DSB can have in dividing cells, the cell needs to take rapid counter measures to (1) stop or delay cell division and (2) repair the DSB. The division of a cell is under the control of cell-cycle checkpoints in the G1, S, G2, and M phases, the activation of which leads to arrest of the normal division process [1]. It is generally assumed that cell-cycle arrest is necessary to provide the cell with enough time to adequately repair the DNA lesion. In the case of DSBs, cell-cycle arrest is thought to be primarily mediated by members of the phosphatidylinositol 3-kinase-like kinase (PIKK) family, which are activated upon the onset of DNA breakage [3-5]. In human cells, the activation of at least two PIKK signalling kinases - the ataxia telangiectasia mutated (ATM) and ataxia telangiectasia related (ATR) proteins - leads to phosphorylation and activation of the central cell-cycle regulators $\mathrm{p} 53, \mathrm{Chk} 1$ and Chk2, which in turn facilitate $\mathrm{G} 1$ and $\mathrm{G} 2$ arrest via $\mathrm{Cdk} 2 / \mathrm{Cyclin} \mathrm{E}$ and Cdk2/Cyclin B1, respectively [4].

While the division of the DSB-containing cell is thus halted, several sets of enzymes work on the repair of the DSB. Two distinctly different pathways that mediate DSB repair have been identified in mammalian cells: homologous recombination (HR) and non-homologous end-joining (NHEJ) [1, 6] (Figure 1). The HR pathway is a very accurate repair mechanism, in which a homologous stretch of DNA on a sister chromatid serves as a template to guide repair of the broken strand. NHEJ, on the other hand, is a 
potentially less accurate form of DSB repair, in which the two termini of the broken DNA molecule are processed to form compatible ends that are directly ligated. Under certain circumstances, this latter method can result in the loss of nucleotides and hence in the loss of genomic integrity. At this point it is not completely clear which factors determine the use of HR versus NHEJ, but the cell-cycle stage must play an important role in this decision. After all, the homologous template necessary for HR is only present during the S and G2 phases of the cell cycle. It is therefore believed that NHEJ, although potentially inaccurate, is the prevailing repair pathway during $\mathrm{G} 1$ and $\mathrm{M}$ phases.

\section{Non-homologous end-joining: the basic mechanism}

The molecular mechanism of the NHEJ process looks deceptively simple: a set of enzymes mediates (1) the capture of both ends of the broken DNA molecule, (2) the formation of a molecular bridge that brings the two DNA ends back together; and (3) the subsequent re-ligation of the broken DNA molecule. In reality, the NHEJ process is rather complex and requires a tightly coordinated interplay between the key enzymes to timely initiate each subset of the entire process. Many of these interactions have not been fully investigated and are still poorly understood.

The NHEJ process (Figure 1B) is initiated by the binding of a protein complex, the $\mathrm{Ku} 70 / 80$ heterodimer, to both ends of the broken DNA molecule. It is currently believed that the association of a DNA end with the Ku heterodimer creates a scaffold for the assembly of the other NHEJ key enzymes. In an early stage of NHEJ-mediated DSB repair, the DNA-Ku scaffold attracts the DNA-dependent protein kinase catalytic subunit $\left(\mathrm{DNA}-\mathrm{PK}_{\mathrm{CS}}\right)$ to the DSB. This kinase has multiple roles, including the formation of a synaptic complex which brings both DNA ends together. Once the two DNA ends have been captured and tethered in a protein complex consisting of $\mathrm{Ku}$ and $\mathrm{DNA}-\mathrm{PK}_{\mathrm{CS}}$, non-ligatable DNA termini must be processed before final repair of the DSB can take place. Several enzymes have been identified, including nucleases and polymerases, that are able to either remove or fill-in single-stranded, noncompatible overhangs. It is this step in the NHEJ process that is considered to be responsible for the occassional loss of nucleotides associated with NHEJ-mediated repair. Finally, the ligase IV/XRCC4 complex catalyses ligation of the processed DNA ends. This ligation reaction may be enhanced by the presence of the recently discovered $\mathrm{XLF} /$ Cernunnos protein.
A
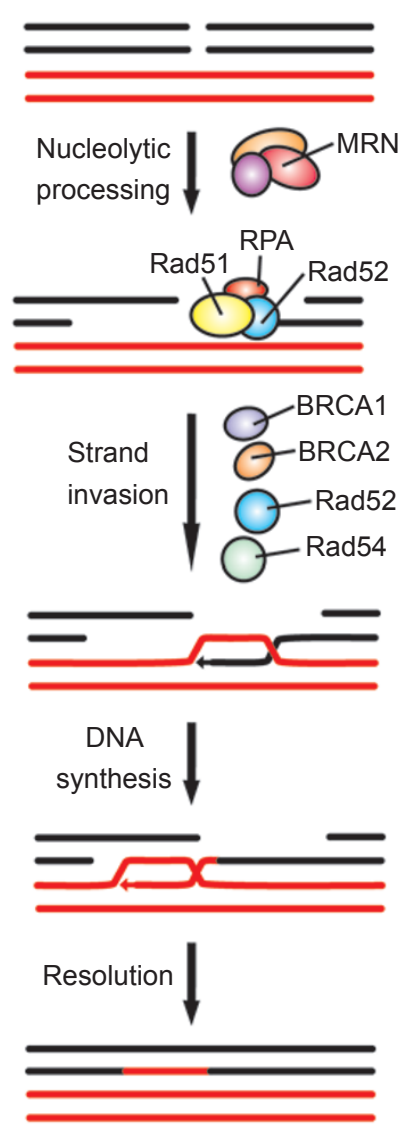

B

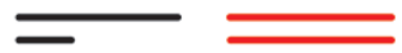

Binding of Ku70/80,
DNA-PKcs

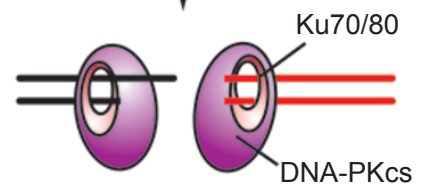

Synaptic
complex
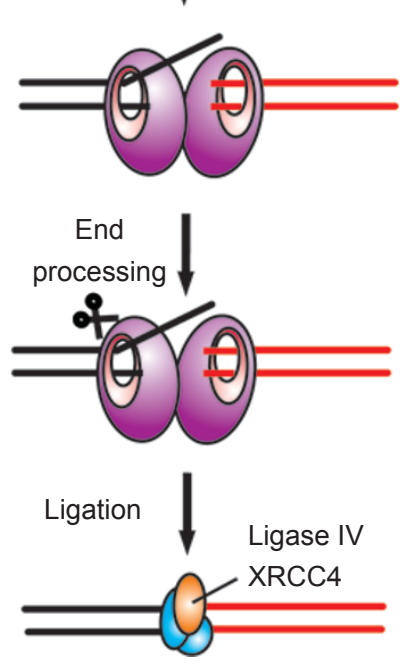

Figure 1 Simplified overview of homologous recombination (HR) and non-homologous end-joining (NHEJ). (A) HR utilizes a homologous stretch on a sister chromatid to accurately repair the DSB. DNA ends are first processed in order to create single-strand overhangs, a process that is likely mediated by the MRN (Mre11/Rad50/Nbs1) complex. Rad51, Rad52, and RPA associate with these overhangs, followed by the formation of a joint molecule by the damaged and undamaged strands. Template guided DNA synthesis and resolution of the two strands then complete repair of the DSB. (B) NHEJ brings the ends of the broken DNA molecule together by the formation of a synaptic complex, consisting of two DNA ends, two Ku70/80 and two DNA-PK $\mathrm{C}_{\mathrm{cs}}$ molecules. Noncompatible DNA ends are processed to form ligatable termini, followed by repair of the break by the ligase IVIXRCC4 complex. 
Non-homologous end-joining and V(D)J recombination: where immunology and DNA repair meet

DSBs are not only introduced by exposure to mutagenic agents or radiation. They are also continuously generated in developing B- and T-lymphocytes. This is due to the fact that the genes which encode immunoglobulins (Ig) or T-cell receptors (Tcr) are not present in an active form in these lymphocytes. The formation of active Ig or Tcr genes requires the combination of gene segments by a process called V(D)J recombination, which mediates the excision, relocation, and re-ligation of these gene segments in a manner that utilizes several of the NHEJ key enzymes [6, 7]. The sheer endless number of combinations that can be made with those segments accounts for the great potential of the immune system to recognize a wide range of immunogens (Figure 2).

The gene segments are classified into different groups, which are called variable (V), diversity (D), and joining (J) segments. Active IgH genes are made by the selection and coupling of a D and a $\mathrm{J}$ segment, followed by the coupling of the DJ assembly with a V segment. This coupling takes place by the introduction of a DSB at the edge of the selected gene segment, removal of the intervening DNA, and ligation of the gene segment with its designated partner. DSBs are introduced during V(D)J recombination by the RAG1 and RAG2 (Recombination-Activating Genes) proteins at specific sites: the recombination signal sequences. The ends of the gene segments that are to be joined in order to form the mature Ig or Tcr gene are called coding ends. Coding ends are characterized by a hairpin structure that needs to be opened before end-joining can proceed (Figure 2).

The opening of the coding end hairpin structures is mediated by the Artemis nuclease, which is essential for $\mathrm{V}(\mathrm{D}) \mathrm{J}$ recombination $[8,9]$. The Artemis protein forms a complex with the NHEJ factor DNA-PK $\mathrm{CS}_{\mathrm{CS}}$. This association activates the Artemis endonuclease and enables opening of the coding end hairpins, facilitating subsequent ligation of the V, D, or J gene segments [10]. Ligation of these segments requires the presence of the NHEJ core factors ligase IV and XRCC4, indicating that repair of the RAGinduced DSBs during $\mathrm{V}(\mathrm{D}) \mathrm{J}$ recombination is mediated by the NHEJ process $[6,7]$.

\section{The early stages of non-homologous end-joining}

It is generally assumed that the $\mathrm{Ku} 70 / 80$ heterodimer and the DNA-PK ${ }_{C S}$ kinase are recruited to the DSB site in the earliest stages of the NHEJ process. Several recent studies have demonstrated that $\mathrm{Ku} 70 / 80$ and DNA-PK $\mathrm{CS}_{\text {migrate }}$ towards artificially introduced DSBs in living cells in a

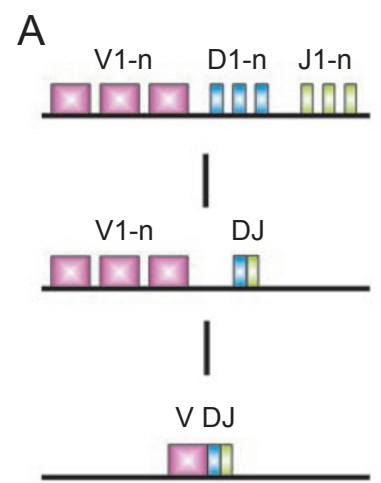

B

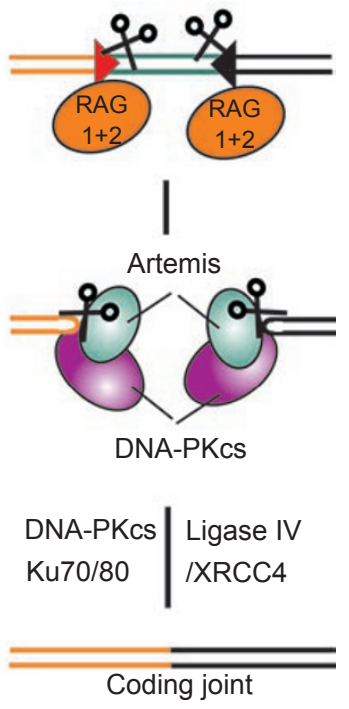

Figure 2 Simplified overview of V(D)J recombination. (A) Genes that encode immunoglobulins or T-cell receptors are not present in an active form in developing B- and T-lymphocytes, but need to be formed by the combination of gene segments. This process is called V(D)J recombination. Gene segments are classified into three groups: variable $(V)$, diversity $(D)$, and joining $(J)$ segments. In the case of an IgH gene, $D$ and $J$ segments are first joined, followed by the combination of the DJ assembly with a $\mathrm{V}$ segment. (B) Gene segments are joined by the introduction of a DSB at the edges of selected segments by the RAG 1 and RAG 2 proteins, followed by removal of the intervening DNA and ligation of the segments. Before ligation can take place, the typical hairpin structure of the coding ends needs to be opened by the endonuclease Artemis. $V(D) J$ recombination requires the NHEJ core enzymes (DNA-PK $\mathrm{cs}_{\mathrm{cs}}, \mathrm{Ku} 70 / 80$, ligase IV, and XRCC4), indicating that ligation of the gene segments is mediated by the NHEJ process.

manner of seconds after the onset of the damage [11, 12].

The extraordinary high affinity of Ku70/80 for DNA termini and its abundant concentration in the cell nucleus make it very likely that this protein dimer associates with the ends of a broken DNA molecule immediately after the introduction of the break. Crystallography studies of $\mathrm{Ku} 70 / 80$ revealed that the heterodimer has an open ringshaped structure, composed of one Ku70 (73 kDa) and one $\mathrm{Ku} 80(86 \mathrm{kDa})$ protein which both constitute part of the ring [13]. This hetero-dimerization is mediated mainly by the central regions of both the $\mathrm{Ku} 70$ and $\mathrm{Ku} 80$ proteins [13, 14] (Figure $3 \mathrm{~A}$ ). The opening of the ring accommodates a DNA helix and this feature allows the Ku70/80 dimer to slide over the ends of a broken DNA molecule, thus accounting for the high affinity of Ku70/80 for DNA termini [13]. The central regions of both the $\mathrm{Ku} 70$ and the $\mathrm{Ku} 80$ protein, which are located on the inside of the ring, assume a threedimensional structure that sterically fits the DNA helix, 
but makes little direct contact with the DNA backbone or bases [13] (Figure 3A). Indeed, careful examination of the dynamics of Ku80 molecules at DSB sites in living cells has revealed that $\mathrm{Ku}$ does not bind rigidly to DNA ends, but that there is a continuous dynamic exchange between DNA-bound $\mathrm{Ku}$ and free, unbound $\mathrm{Ku}$ [12].

The Ku-DNA complex acts as a scaffold for the association of a $460-\mathrm{kDa}$ serine/threonine kinase: DNA-PK $\mathrm{CS}_{\text {. }}$ This interaction between $\mathrm{Ku}$ and $\mathrm{DNA}-\mathrm{PK}_{\mathrm{CS}}$ is thought to be mediated by the Ku80 carboxy-terminus [15-17] (Figure 3A). The three dimensional structure of the DNA
- $\mathrm{Ku}$ - DNA-PK $\mathrm{CS}_{\mathrm{S}}$ complex has not been resolved by crystallography studies, but electron microscopy images are available at a $25 \mathrm{~A}$ level [18-20]. Interestingly, these images show dimeric structures in which two DNA ends are tethered by a protein complex consisting of two Ku70/80 dimers and two DNA-PK $\mathrm{CS}_{\mathrm{CS}}$ molecules, suggesting that DNA-PK $\mathrm{CS}_{\mathrm{CS}}$ is capable of forming a 'bridge' between two DNA molecules. This hypothesis is further evidenced by atomic force microscopy studies, which demonstrate the presence of DNA-PK ${ }_{\mathrm{CS}}$ at juxtaposed DNA ends [21]. In addition, biochemical experiments have shown that DNA

A

B

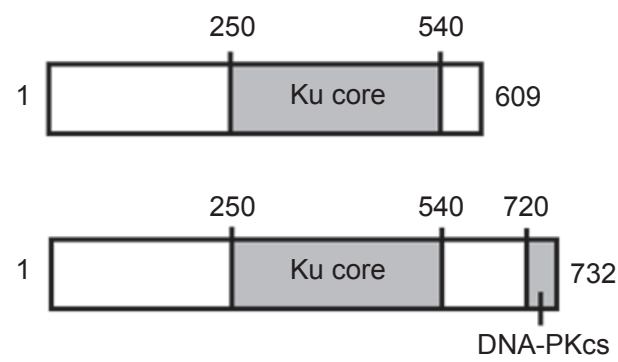

interaction

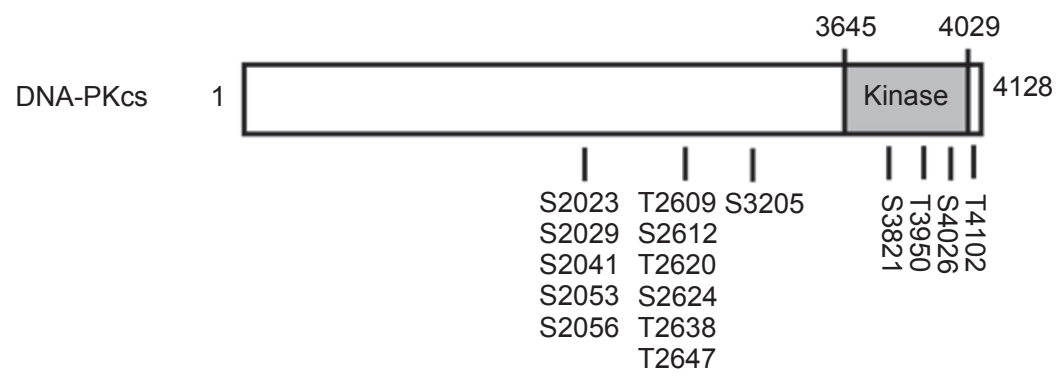

C

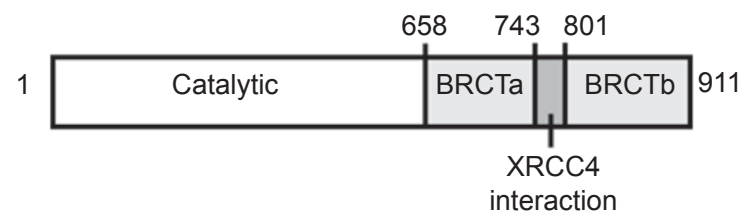

D

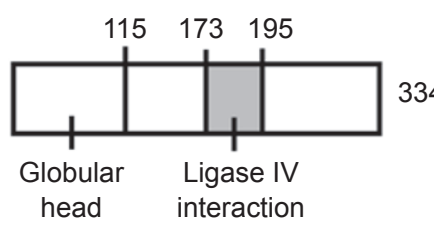

(755-782)

XRCC4

Figure 3 Schematic representations of the human NHEJ core enzymes. Drawings are not to scale. (A) The central regions of the Ku70 and the Ku80 protein (the 'Ku core' domains, roughly encompassing residues 250-540) mediate both the hetero-dimerization of Ku70 and Ku80 and the interaction of the Ku70/80 heterodimer with the DNA helix [13]. The association of the Ku70/80 heterodimer with DNA-PK is thought to be mediated by the extreme carboxy-terminus of Ku80 [16, 17]. (B) The serine/threonine kinase domain of DNA-PK $\mathrm{CS}_{\mathrm{S}}$ is located in the carboxy-terminus, between residues 3645 and 4029 . All known phosphorylation sites are indicated: the 2056 cluster, the 2609 cluster, and the carboxy-terminal cluster [35]. (C) The ligase IV protein possesses a BRCT tandem that encompasses residues 658-911, but the domain that mediates the interaction between ligase IV and XRCC4 is located in between the two BRCT regions, spanning residues 755-782 [58]. Several domains necessary for the catalytic activity of ligase IV are situated in the amino-terminal region [54]. (D) The first 115 amino acids of the XRCC4 protein form a globular head [59], while the rest of the molecule forms a long stalk which interacts with ligase IV between residues 173 and 195 [58]. 
molecules can be held together by the DNA-PK $\mathrm{CS}_{\mathrm{CS}}$ protein [22]. Collectively, these data led to the current notion that DNA-PK ${ }_{\mathrm{CS}}$ mediates tethering of the ends of a broken DNA molecule by binding to the DNA-Ku scaffold and by subsequently forming a synaptic complex that juxtaposes two DNA termini, two Ku dimers and two DNA-PK ${ }_{\mathrm{CS}}$ molecules (Figure 1B).

The intimate association of DNA-PK $\mathrm{CS}_{\mathrm{CS}}$ with both a DNA terminus and a $\mathrm{Ku}$ dimer is necessary for the activation of the DNA-PK $\mathrm{CS}_{\mathrm{CS}}$ serine/threonine kinase, located at the carboxy-terminus of the DNA-PK $\mathrm{CS}_{\mathrm{CS}}$ molecule (Figure 3B). The role of the DNA-PK $\mathrm{CS}_{\mathrm{C}}$ kinase within the NHEJ process is not completely resolved at this point, although it is clear that this activity is required for efficient NHEJ [23]. No evidence is available that the DNA-PK $\mathrm{CS}_{\mathrm{CS}}$ kinase activity is necessary for the formation of the synaptic complex as described above. Several targets of the DNA-PK $\mathrm{CS}_{\mathrm{C}}$ kinase have been identified in vitro, including components of the NHEJ repair complex (XRCC4 and Ku70/80) and the cellcycle regulator p53 $[24,25]$. The fact that DNA-PK $\mathrm{CS}_{\mathrm{CS}}$ is able to phosphorylate these targets suggests a role in either cell cycle arrest or regulation of the NHEJ process itself. However, the in vivo significance of DNA-PK $\mathrm{CS}_{\mathrm{CS}}$ mediated phosphorylation of XRCC4, Ku70/80, and p53 has not been conclusively demonstrated or is disputed [26-28].

The most extensively studied target of the DNA-PK $\mathrm{CS}_{\mathrm{Ki}}$ nase is DNA-PK $\mathrm{CS}_{\mathrm{S}}$ itself. Currently, there are 16 amino-acid residues identified within the DNA-PK $\mathrm{CS}_{\mathrm{CS}}$ molecule that can be autophosphorylated by the DNA-PK $\mathrm{CS}_{\mathrm{C}}$ kinase (Figure 3B). It has been well established that this autophosphorylation activity is important for the efficient progression of the NHEJ process, since mutation of several autophosphorylation sites results in diminished DSB repair and sensitivity of cells to DSB-inducing ionizing radiation [29-34].

How does DNA-PK $\mathrm{CS}_{\mathrm{C}}$ autophosphorylation facilitate NHEJ-mediated DSB repair? The phosphorylation status of the DNA-PK $\mathrm{CS}_{\mathrm{CS}}$ molecule is known to influence its conformation and dynamics at the synaptic complex [35]. The presence of the large DNA-PK $\mathrm{CS}_{\mathrm{CS}}$ molecule in its unphosphorylated form at the DNA termini effectively blocks the access of processing enzymes and ligases to the synaptic complex and inhibits effective ligation of the two DNA ends [36-38]. Obviously, this blockage needs to be relieved before the NHEJ process can progress further. It has been demonstrated that autophosphorylation of DNA-PK $\mathrm{CS}_{\mathrm{C}}$ is required to introduce a change in the DNA - DNA-PK ${ }_{C S}$ complex which relieves the blockage and allows processing and ligation of the DNA termini [37-39]. Recently, it has been shown that DNA-PK $\mathrm{CS}_{\mathrm{C}}$ autophosphorylation can occur in trans at the synaptic complex, suggesting that autophosphorylation takes place when the synapsis between the two DNA ends with bound $\mathrm{Ku}$ and DNA-PK $\mathrm{CS}_{\mathrm{CS}}$ is established
[40]. Taken together, these findings gave rise to the current notion that the presence of unphosphorylated DNA-PK $\mathrm{CS}_{\mathrm{CS}}$ protects the DNA termini against premature degradation or ligation until both ends of the broken DNA molecule are properly brought together in the synaptic complex. Trans autophosphorylation then introduces a conformational

A
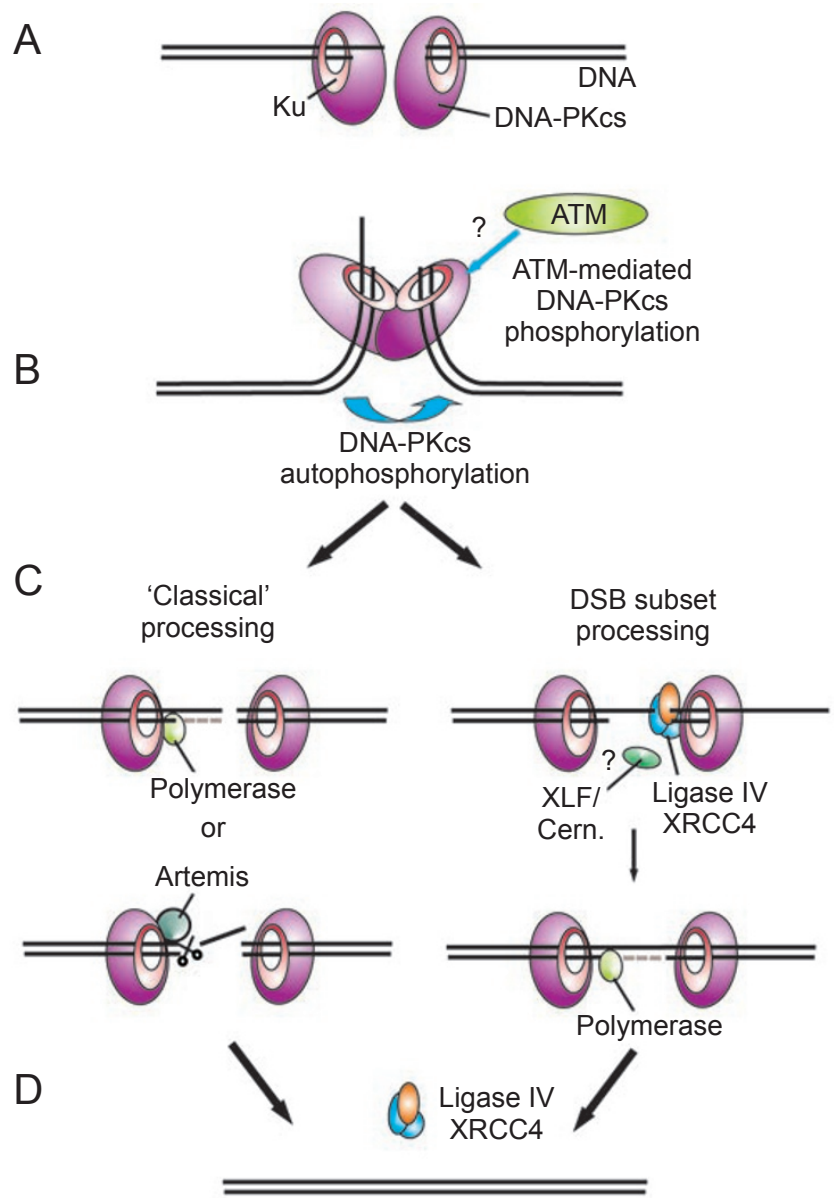

Figure 4 A model for NHEJ. (A) The Ku70/80 heterodimer associates with the two ends of the broken DNA molecule. This DNA-Ku scaffold attracts DNA-PK $\mathrm{CS}_{\mathrm{CS}}$, which protects the DNA termini against degradation and premature ligation. (B) The DNA-PK $\mathrm{CS}_{\mathrm{cs}}$ molecules on both DNA ends form a synaptic complex which tethers the DNA ends. Trans DNA-PK cs autophosphorylation then introduces a conformational change that makes the DNA termini accessible for other NHEJ enzymes. In addition to autophosphorylation, ATM-mediated DNA-PK cs phosphorylation may play a role in this conformational change. (C) Non-compatible DNA termini need to be processed before ligation can proceed. This can be done in the 'classical' way, by either filling (polymerases) or resection (Artemis) of single-strand overhangs, followed by (D) ligation of the blunted ends by ligase IV/XRCC4. Alternatively, in a subset of DSBs with partially complementary overhangs, ligase IV/XRCC4 and XLF/Cernunnos mediate the joining of one single-strand overhang with the opposite DNA end, followed by filling of the gap by polymerases. 
change in the DNA-PK $\mathrm{CS}_{\mathrm{CS}}$ molecule that results in accessibility of the DNA ends for processing enzymes and ligases (Figure 4). To date, the nature of this conformational change has not been further investigated. Analysis of the dynamics of phosphorylated and unphosphorylated DNA-PK $\mathrm{CS}_{\mathrm{CS}}$ at DSB sites in vivo revealed that the exchange between DNAbound and free DNA-PK $\mathrm{CS}_{\mathrm{CS}}$ progresses at a much lower rate in the case of unphosphorylated DNA-PK $\mathrm{CS}_{\mathrm{CS}}$, suggesting that the autophosphorylation-induced conformational change increases the rate of dissociation and re-association of DNA-PK $\mathrm{CS}_{\mathrm{C}}$ at DNA termini. This increased exchange rate is likely to also increase the window of time that is available for processing or ligating enzymes to associate with the DNA ends [11].

Future research will have to unravel the role that each DNA-PK $\mathrm{CS}_{\mathrm{C}}$ phosphorylation site plays during the conformational changes that facilitate access to the DNA ends. It appears that the phosphorylation sites in the DNA-PK $\mathrm{CS}_{\mathrm{C}}$ molecule are arranged in three major clusters: five residues in the 2056 cluster, six residues in the 2609 cluster, and four residues in the carboxy-terminus (Figure 3B). The 2609 cluster is the most extensively studied. Inhibition of phosphorylation of the residues in this cluster severely decreases DNA end processing [30]. This effect is strongest when phosphorylation of all residues is inhibited, suggesting that the residues within the 2609 cluster cooperate in facilitating DNA end accessibility. Only one study has been devoted to the role of the 2056 cluster, which demonstrates that phosphorylation of this cluster may inhibit end processing [32]. It therefore appears that the 2056 and 2609 clusters have opposing activities, although this finding will need further experimental evidence. Of the carboxy-terminal cluster, only the 3950 residue has been subjected to close examination. This phosphorylation site is located within the serine/threonine kinase domain of DNA-PK $\mathrm{CS}_{\mathrm{CS}}$ (Figure 3B) and mutation of the 3950 residue with phosphomimic aspartic acid results in abrogated $\mathrm{V}(\mathrm{D}) \mathrm{J}$ recombination, sensitivity to ionizing radiation, and hence in reduced DSB repair [33]. In view of its location within the kinase domain, it is tempting to speculate that the 3950 residue may modulate $\mathrm{DNA}-\mathrm{PK}_{\mathrm{CS}}$ autophosphorylation by regulating kinase activity.

Recent reports have shown that the 2609 and 2647 residues of DNA-PK $\mathrm{CS}_{\mathrm{C}}$ are still being phosphorylated in the absence of a functional DNA-PK $\mathrm{CS}_{\mathrm{CS}}$ kinase after the introduction of DSBs in vivo [11, 41]. These findings suggest that some DNA-PK $\mathrm{CS}_{\mathrm{CS}}$ phosphorylation sites can be phosphorylated by kinases other than the DNA-PK $\mathrm{CS}_{\mathrm{C}}$ kinase. One study finds the availability of the PIKK kinase ATM necessary for phosphorylation of the 2609 and 2647 residues [41]. Another study finds no absolute requirement for $\mathrm{ATM}$, but does conclude that DNA-PK $\mathrm{CS}_{\mathrm{C}}$ phosphorylation occurs to a limited extent under conditions that exclude autophosphorylation [40]. Since ATM is known to be present at DSB sites in vivo [42], it is conceivable that the full array of phosphorylation events that lead to the conformational changes in the DNA-PK $\mathrm{CS}_{\mathrm{CS}}$ molecule is mediated by both the ATM kinase and the DNA-PK $\mathrm{CS}_{\mathrm{CS}}$ kinase [35] (Figure 4).

\section{The later stages of non-homologous end-joining}

It is not easy to make a clear distinction between the early and later stages of the NHEJ process, because it is possible that the enzymes that act in the later stages of NHEJ (processing enzymes and ligases) are already associated with the synaptic repair complex since the initiation of the process. The DNA-Ku scaffold is able to attract more

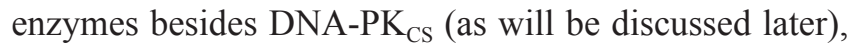
suggesting that early association of processing enzymes, ligase IV/XRCC4 and XLF/Cernunnos with the synaptic complex is possible. However, relevant knowledge about the exact timing of the recruitment of these enzymes to the repair complex is lacking at this point. Because ligation cannot proceed before proper processing of the DNA ends is completed, and because processing cannot proceed without phosphorylation of DNA-PK $\mathrm{CS}_{\mathrm{CS}}$, we arbitrarily denote processing and ligation as the 'later' stages of NHEJ-mediated repair.

Reactive oxygen species and ionizing radiation introduce a rather heterogeneous array of DSBs. The simplest DSB form is one that consists of two blunt DNA termini. Such termini would not require processing and could be directly ligated. But in the majority of cases the two DNA termini will not be directly compatible because at least one of the strands will have a $3^{\prime}$ or $5^{\prime}$ single-strand overhang. The size of this overhang depends on the relative distance between the positions where each of the two strands of the DNA backbone was severed. There are two ways by which a single-strand DNA overhang can be removed: either by using the nucleotide sequence of the overhang as a template to synthesize the complementary strand or by resection of the overhang at the position where the single-strand segment extends from the double-strand helix (Figure 4).

Several enzymes capable of synthesizing a complementary strand by adding nucleotides have been shown to play a role in NHEJ. Human terminal deoxynucleotidyltransferase (TdT) co-localizes with $\mathrm{Ku}$ at DSB sites, indicating that this enzyme may be attracted by the DNA-Ku scaffold and functions as a processing factor during NHEJ mediated DSB repair [43, 44]. DNA polymerase $\mu$ is also suggested to interact with $\mathrm{Ku}$ and stimulates end-joining in vitro [45]. Similarly, depletion of DNA polymerase $\lambda$ from a HeLa extract reduced end-joining in an in vitro assay [46]. Notably, 
all these enzymes have functions during other cellular processes and cannot be considered specialized NHEJ factors. It appears that the NHEJ process utilizes DNA modifying factors that belong to the general enzymatic pool of the cell. At present, it is not known which factor or process determines which modifying enzyme is to be used during the processing of a specific set of DNA termini.

As far as resection of single-strand overhangs is concerned, only one enzyme has been demonstrated to perform this task during NHEJ: the endonuclease Artemis. This enzyme was initially recognized as an essential factor during $\mathrm{V}(\mathrm{D}) \mathrm{J}$ recombination, facilitating the opening of hairpin structures at coding ends [8-10]. However, since Artemis deficiency not only causes impairment of V(D)J recombination but also sensitivity to ionizing radiation, it is likely that Artemis plays an important role during repair of radiation-induced DSBs. The Artemis protein by itself only displays a 5'-3' exonuclease activity. In order to acquire the endonuclease activity that mediates hairpin opening during $\mathrm{V}(\mathrm{D}) \mathrm{J}$ recombination, Artemis must associate with the DNA-PK $\mathrm{CS}_{\mathrm{S}}$ molecule [10]. This association of Artemis and DNA-PK ${ }_{C S}$ is most likely responsible for the recruitment of Artemis to the synaptic repair complex, although it is not known during which phase of the NHEJ process Artemis is drawn to the DSB site. Both the DNA-PK ${ }_{\mathrm{CS}}$-independent exonuclease activity and the DNA- $\mathrm{PK}_{\mathrm{CS}}$-dependent endonuclease activity of Artemis can be relevant for processing of DNA termini during repair of radiation-induced DSBs. It is therefore unclear whether the association of Artemis with DNA-PK $\mathrm{CS}_{\mathrm{S}}$ is only necessary for the physical attachment of Artemis to the repair complex or that it is also essential to expand the nucleolytic potential of the Artemis enzyme.

After exposure of cells to ionizing radiation, Artemis is (hyper)phosphorylated by both the ATM and DNA-PK ${ }_{C S}$ kinases [47]. At present it is not yet resolved whether this phosphorylation is required for activity of the Artemis nuclease, because contradicting information on this topic has been presented. One report shows the involvement of DNA-PK $\mathrm{CS}_{\mathrm{S}}$ in phosphorylation of the carboxy-terminal part of Artemis, thereby relieving auto-inhibition of the Artemis endonuclease activity [48]. Contrary, another report suggests that the DNA-PK ${ }_{C S}$ kinase is not essential for Artemis endonuclease activation, but rather for DNA-PK $\mathrm{CS}_{\mathrm{C}}$ autophosphorylation which facilitates access of Artemis to the DNA termini as explained in the previous section [49].

Processing of DNA ends is not limited to filling or resection of single-stranded overhangs. It can also include the addition of $5^{\prime}$ phosphate groups which are necessary for the ligation reaction. This activity is mediated by the mammalian polynucleotide kinase (PNK) in an XRCC4and DNA-PK $\mathrm{CS}_{\mathrm{C}}$-dependent manner [50]. In certain cases, 3' phosphoglycolates must be removed before ligation can take place. This task can be performed by the apurinic/apurinic endonuclease APE1, the tyrosyl-DNA phosphodiesterase TDP1, the polynucleotide kinase PNK and the endonuclease Artemis [51, 52]. Although these four enzymes have very different catalytic activities, together they are able to recognize a wide variety of DNA substrates [51].

After proper processing of the DNA termini, the stage is set for the final repair of the broken DNA molecule. During the previously discussed steps of the NHEJ process, the DNA ends have been tethered in a synaptic complex and non-compatible overhangs were transformed into $5^{\prime}$ phosphorylated, ligatable ends (Figure 4). Ligation of these processed DNA termini is mediated by a complex of two proteins: ligase IV and XRCC4. The importance of these enzymes during DSB repair is clearly demonstrated by the fact that deficiency in either of them leads to embryonic lethality in mice and that ligase IV- and XRCC4-deficient cells are sensitive to ionizing radiation [6].

The catalytic domain of the $100 \mathrm{kDa}$, ATP utilizing ligase IV protein is located in the amino-terminal region, which shares distinct homology with the other main mammalian ligases: ligase I and III $[53,54]$. Contrary to the amino terminus, the carboxy terminus of ligase IV is a rather unique structure and contains two regions that harbour a BRCT (BRCA1 carboxy-terminus like) motif: an approximately 95 amino-acid spanning sequence that is known to be involved in protein-protein interaction, especially with BRCT domains in other proteins [55] (Figure 3C). Interestingly, however, the interaction between ligase IV and XRCC4 is not thought to be mediated by the BRCT motifs themselves, but by the sequence that lays in between the two BRCT domains, encompassing amino-acids 755 to 782 [56-58].

The crystal structure of XRCC4 reveals that this protein has a globular amino-terminal head and a long carboxyterminal stalk [59]. The amino-terminal head most likely interacts with DNA and the carboxy-terminal region between amino acids 173 and 195 mediates the interaction between XRCC4 and ligase IV [58] (Figure 3D). The threedimensional structure of the ligase IV/XRCC4 complex shows two XRCC4 molecules that are positioned side by side with the two carboxy-terminal stalks extending more or less in a parallel fashion, while one ligase IV molecule is associated with the combined stalks of the XRCC4 dimer $[58,60]$. In view of this structure, it is likely that the amino-terminal heads of the XRCC4 molecules mediate an interaction with the DNA helix, while the ligase IV enzyme repairs the DSB.

Several studies have demonstrated interactions between the ligase IV/XRCC4 complex and the Ku70/80 heterodimer, suggesting that the ligase IV/XRCC4 complex is attracted to the synaptic repair complex by the DNA-Ku 
scaffold in a manner similar to the recruitment of DNA$\mathrm{PK}_{\mathrm{CS}}$ and several of the processing enzymes [12, 61-64]. The BRCT motifs of ligase IV may be involved in the interaction of the ligase IV/XRCC4 complex with Ku70/80 [64]. One in vitro study has shown that the ligation activity of ligase IV/XRCC4 increases 20-fold upon interaction with $\mathrm{Ku} 70 / 80$, suggesting that $\mathrm{Ku}$ not only recruits but also activates ligase IV/XRCC4 [61]. It is unknown at present, during which stage of the NHEJ process ligase IV/XRCC4 associates with the DNA-Ku scaffold. It is possible that the ligase IV/XRCC4 complex binds simultaneously with DNA-PK $\mathrm{CS}_{\mathrm{CS}}$ to the DNA termini and awaits its turn until DNA-PK $\mathrm{CS}_{\mathrm{C}}$ phosphorylation has mediated accessibility of the DNA ends. On the other hand, ligase IV/XRCC4 may join the repair complex only after tethering and processing of the DNA termini.

Several authors have introduced interesting models in which the ligase IV/XRCC4 complex not only facilitates the finishing touch of the NHEJ process but also has an important function in the initiation of DNA end processing in a subset of DSBs. In these models, Ku and ligase IV/XRCC4 cooperate in the positioning of incompatible, unprocessed DNA ends in such a way that the overhanging strand of one DNA terminus is joined with the opposite DNA terminus (Figure 4). This creates a structure in which two duplex DNA strands are joined by a short single-stranded stretch, which can be filled in by polymerases [51, 65-69]. This kind of alternative processing may be possible when the single-strand overhang is partially complementary with the opposite DNA end. Clearly, in such cases, end processing and ligation cannot be considered to be two distinctly separated processes but they are in fact joined in one cooperative effort.

In 2006, two research groups simultaneously identified a novel factor with a clear significance for NHEJ. One group named this factor Cernunnos [70], and the other group named it XRCC4-like factor (XLF) [71]. As the latter name suggests, this $33 \mathrm{kDa}$ protein displays sequence and structure homology with XRCC4. The XLF/Cernunnos factor was discovered after reports of a cell line that exhibited DSB repair and V(D)J recombination deficiencies (2BN), but could not be complemented with the known NHEJ genes [72]. XLF/Cernunnos was found to rescue the defects of the $2 \mathrm{BN}$ cells, demonstrating the involvement of $\mathrm{XLF} / \mathrm{Cernunnos}$ in NHEJ-mediated DSB repair $[71,73]$. Information on the factors that influence the recruitment of $\mathrm{XLF} /$ Cernunnos to the synaptic repair complex is limited, although it has been demonstrated that this recruitment may depend on the availability of ligase IV/XRCC4 [71] and Ku70/80 (Ken-ichi Yano, EMBO Rep in progress).

The XLF/Cernunnos factor interacts with the ligase IV/XRCC4 complex, suggesting that XLF/Cernunnos stimulates or modulates the ligation efficiency of ligase IV/XRCC4 [71]. Recent studies demonstrate that XLF/ Cernunnos stimulates the ligation of non-compatible DNA ends $[66,74]$. In the presence of XLF/Cernunnos, two DNA substrates (one with a blunt end and one with a $3^{\prime}$ overhanging end) were ligated at the overhanging strand, leaving the other strand unligated [66]. The non-ligated strand could theoretically be a substrate for a polymerase that fills in the gap and facilitates complete repair of the break. By stimulating ligation of non-compatible ends XLF/ Cernunnos may be able to prevent resection of single-strand overhangs, thereby greatly contributing to the preservation of the DNA sequence and the prevention of nucleotide loss during NHEJ.

\section{Concluding remarks}

The functions of the NHEJ core factors and the processing enzymes cannot be understood without a thorough knowledge of the multiple interactions that these factors have with each other. The DNA - Ku scaffold seems to play an especially important role in the NHEJ process, since it is known to associate with all the other factors: $\mathrm{DNA}-\mathrm{PK}_{\mathrm{CS}}$, ligase IV/XRCC4, XLF/Cernunnos, and the processing polymerases. The NHEJ pathway can be roughly divided into two phases: an early phase and a late phase, although it may well be possible that contributors of the early phase may be present and active during the late phase and vice versa. The early phase constitutes the recruitment of $\mathrm{Ku} 70 / 80$ to the ends of the broken DNA molecule, the binding of DNA-PK $\mathrm{CS}_{\mathrm{S}}$ to the DNA - Ku complex, the formation of a synaptic complex that tethers the two DNA ends, and the regulation of DNA end accessibility by phosporylation events within the DNA-PK $\mathrm{CS}_{\mathrm{C}}$ molecule (Figure 4). After the DNA termini are made accessible by DNA-PK $\mathrm{CS}_{\mathrm{C}}$ phosphorylation, the stage is set for the late phase: processing and ligation of the DNA termini. Classical models depict the processing step as a process that is separate from and precedes the activity of the ligase IV/XRCC4 complex. Modern insights, however, have revealed that at least for a certain subset of DSBs, especially those with at least partially complementary overhangs, ligase IV/XRCC4 and $\mathrm{Ku}$ may align the DNA ends prior to processing. This mode of action, perhaps stimulated by XLF/Cernunnos, would allow ligation of one strand, leaving a gap at the other strand that can be filled in by a polymerase (Figure 4). It will be one of the important tasks for future researchers to investigate the plausibility of this combined processing/ligation model.

The working model for the NHEJ mechanism is far from resolved and many questions remain to be answered. We provide here a brief overview of some issues that will need to be addressed in the near future: (1) The fate of the 
Ku70/80 molecule after repair of the DSB. To our knowledge, no experiments have been published that shed light on the fate of the $\mathrm{Ku} 70 / 80$ ring after recruitment of the NHEJ key enzymes. The high affinity of Ku70/80 for DNA termini makes it unlikely that it would dissociate from the DNA helix, unless some conformational change is introduced in the $\mathrm{Ku} 70 / 80$ molecule via its interaction with one of the other NHEJ enzymes. It is possible that the $\mathrm{Ku} 70 / 80$ ring still encircles the DNA helix after repair of the DSB. In that case, the heterodimer will have to be removed by the action of a still unidentified protease. (2) The nature of the conformational change that takes place after DNA-PK $\mathrm{CS}_{\mathrm{C}}$ autophosphorylation. Although it has been shown that phosphorylation of the 2609 cluster is required for effective DSB repair, the effects brought on by phosphorylation of the other 10 residues within the DNA-PK ${ }_{C S}$ molecule remain somewhat elusive. Next to nothing is known about the influence of DNA-PK ${ }_{\mathrm{CS}}$ phosphorylation on its threedimensional structure. (3) The requirement for Artemis phosphorylation during activation of its endonuclease. The relevance of DNA-PK $\mathrm{CS}_{\mathrm{CS}}$-mediated phosphorylation of Artemis during DSB repair is a matter of current debate and the function of ATM-mediated phosphorylation of Artemis is even less well understood. These three examples are merely a selection of the current questions within the field and they clearly show that there are still many opportunities for scientists to fill knowledge gaps and add to the seemingly endless tale of non-homologous end-joining.

\section{Acknowledgments}

We are grateful to Drs Anthony J Davis, Michael D Story, Sandeep Burma, and Laura Ortega (Department of Radiation Oncology, Division of Molecular Radiation Biology, University of Texas Southwestern Medical Center) for critical revision of the manuscript. This work was supported by NIH (USA) Grants R37-CA050519 and PO1CA92584, and by NASA Grant NNA05CM04G. Due to the large number of publications on the subject of NHEJ, we sometimes refer to reviews instead of original publications. We therefore apologize to all colleagues whose work we did not specifically mention in this paper. Eric dedicates this work to Joanne, with love.

\section{References}

1 Hoeijmakers JH. Genome maintenance mechanisms for preventing cancer. Nature 2001; 411:366-374.

2 van Heemst D, den Reijer PM, Westendorp RG. Ageing or cancer: a review on the role of caretakers and gatekeepers. Eur J Cancer 2007; 43:2144-2152.

3 Durocher D, Jackson SP. DNA-PK, ATM and ATR as sensors of DNA damage: variations on a theme? Curr Opin Cell Biol 2001;

\section{3:225-231}

4 Khanna KK, Jackson SP. DNA double-strand breaks: signaling, repair and the cancer connection. Nat Genet 2001; 27:247-254.

5 Lobrich M, Jeggo PA. The two edges of the ATM sword: cooperation between repair and checkpoint functions. Radiother Oncol 2005; 76:112-118.

6 van Gent DC, Hoeijmakers JH, Kanaar R. Chromosomal stability and the DNA double-stranded break connection. Nat Rev Genet 2001; 2:196-206.

7 Gellert M. V(D)J recombination: RAG proteins, repair factors, and regulation. Annu Rev Biochem 2002; 71:101-132.

8 Rooney S, Sekiguchi J, Zhu C, et al. Leaky Scid phenotype associated with defective V(D)J coding end processing in Artemisdeficient mice. Mol Cell 2002; 10:1379-1390.

9 Moshous D, Callebaut I, de Chasseval R, et al. Artemis, a novel DNA double-strand break repair/V(D)J recombination protein, is mutated in human severe combined immune deficiency. Cell 2001; 105:177-186.

10 Ma Y, Pannicke U, Schwarz K, Lieber MR. Hairpin opening and overhang processing by an Artemis/DNA-dependent protein kinase complex in nonhomologous end joining and V(D)J recombination. Cell 2002; 108:781-794.

11 Uematsu N, Weterings E, Yano K, et al. Autophosphorylation of DNA-PK ${ }_{\mathrm{CS}}$ regulates its dynamics at DNA double-strand breaks. J Cell Biol 2007; 177:219-229.

12 Mari PO, Florea BI, Persengiev SP, et al. Dynamic assembly of end-joining complexes requires interaction between $\mathrm{Ku} 70 / 80$ and XRCC4. Proc Natl Acad Sci USA 2006; 103:18597-18602.

13 Walker JR, Corpina RA, Goldberg J. Structure of the Ku heterodimer bound to DNA and its implications for double-strand break repair. Nature 2001; 412:607-614.

14 Cary RB, Chen F, Shen Z, Chen DJ. A central region of Ku80 mediates interaction with Ku70 in vivo. Nucleic Acids Res 1998; 26:974-979.

15 Singleton BK, Torres-Arzayus MI, Rottinghaus ST, Taccioli GE, Jeggo PA. The $\mathrm{C}$ terminus of Ku80 activates the DNA-dependent protein kinase catalytic subunit. Mol Cell Biol 1999; 19:32673277.

16 Gell D, Jackson SP. Mapping of protein-protein interactions within the DNA-dependent protein kinase complex. Nucleic Acids Res 1999; 27:3494-3502.

17 Falck J, Coates J, Jackson SP. Conserved modes of recruitment of ATM, ATR and DNA-PK $\mathrm{CS}_{\mathrm{CS}}$ to sites of DNA damage. Nature 2005; 434:605-611.

18 Spagnolo L, Rivera-Calzada A, Pearl LH, Llorca O. Three-dimensional structure of the human DNA-PK $\mathrm{CS}_{\mathrm{Ku}} / \mathrm{Ku} / \mathrm{Ku} 80$ complex assembled on DNA and its implications for DNA DSB repair. Mol Cell 2006; 22:511-519.

19 Rivera-Calzada A, Spagnolo L, Pearl LH, Llorca O. Structural model of full-length human $\mathrm{Ku} 70-\mathrm{Ku} 80$ heterodimer and its recognition of DNA and DNA-PK ${ }_{\mathrm{CS}}$. EMBO Rep 2007; 8:56-62.

20 Llorca O. Electron microscopy reconstructions of DNA repair complexes. Curr Opin Struct Biol 2007; 17:215-220.

21 Yaneva M, Kowalewski T, Lieber MR. Interaction of DNA-dependent protein kinase with DNA and with $\mathrm{Ku}$ : biochemical and atomic-force microscopy studies. Embo J 1997; 16:5098-5112.

22 DeFazio LG, Stansel RM, Griffith JD, Chu G. Synapsis of DNA ends by DNA-dependent protein kinase. EMBO J2002; 21:31923200 . 
23 Kurimasa A, Kumano S, Boubnov NV, et al. Requirement for the kinase activity of human DNA-dependent protein kinase catalytic subunit in DNA strand break rejoining. Mol Cell Biol 1999; 19:3877-3884.

24 Smith GC, Jackson SP. The DNA-dependent protein kinase. Genes Dev 1999; 13:916-934.

25 Lees-Miller SP, Meek K. Repair of DNA double strand breaks by non-homologous end joining. Biochimie 2003; 85:1161-1173.

26 Lakin ND, Jackson SP. Regulation of p53 in response to DNA damage. Oncogene 1999; 18:7644-7655.

27 Burma S, Kurimasa A, Xie G, et al. DNA-dependent protein kinase-independent activation of p53 in response to DNA damage. J Biol Chem 1999; 274:17139-17143.

28 Douglas P, Gupta S, Morrice N, Meek K, Lees-Miller SP. DNAPK-dependent phosphorylation of $\mathrm{Ku} 70 / 80$ is not required for non-homologous end joining. DNA Repair (Amst) 2005; 4:10061018.

29 Chan DW, Chen BP, Prithivirajsingh S, et al. Autophosphorylation of the DNA-dependent protein kinase catalytic subunit is required for rejoining of DNA double-strand breaks. Genes Dev 2002; 16:2333-2338.

30 Ding Q, Reddy YV, Wang W, et al. Autophosphorylation of the catalytic subunit of the DNA-dependent protein kinase is required for efficient end processing during DNA double-strand break repair. Mol Cell Biol 2003; 23:5836-5848.

31 Chen BP, Chan DW, Kobayashi J, et al. Cell cycle dependence of DNA-dependent protein kinase phosphorylation in response to DNA double strand breaks. J Biol Chem 2005; 280:1470914715.

32 Cui X, Yu Y, Gupta S, Cho YM, Lees-Miller SP, Meek K. Autophosphorylation of DNA-dependent protein kinase regulates DNA end processing and may also alter double-strand break repair pathway choice. Mol Cell Biol 2005; 25:10842-10852.

33 Douglas P, Cui X, Block WD, et al. The DNA-dependent protein kinase catalytic subunit is phosphorylated in vivo on threonine 3950 , a highly conserved amino acid in the protein kinase domain. Mol Cell Biol 2007; 27:1581-1591.

34 Soubeyrand S, Pope L, Pakuts B, Hache RJ. Threonines 2638/2647 in DNA-PK are essential for cellular resistance to ionizing radiation. Cancer Res 2003; 63:1198-1201.

35 Weterings E, Chen DJ. DNA-dependent protein kinase in nonhomologous end joining: a lock with multiple keys? J Cell Biol 2007; 179:183-186.

36 Calsou P, Frit P, Humbert O, Muller C, Chen DJ, Salles B. The DNA-dependent protein kinase catalytic activity regulates DNA end processing by means of $\mathrm{Ku}$ entry into DNA. J Biol Chem 1999; 274:7848-7856.

37 Weterings E, Verkaik NS, Bruggenwirth HT, Hoeijmakers JH, van Gent DC. The role of DNA dependent protein kinase in synapsis of DNA ends. Nucleic Acids Res 2003; 31:7238-7246.

38 Block WD, Yu Y, Merkle D, et al. Autophosphorylation-dependent remodeling of the DNA-dependent protein kinase catalytic subunit regulates ligation of DNA ends. Nucleic Acids Res 2004; 32:4351-4357.

39 Reddy YV, Ding Q, Lees-Miller SP, Meek K, Ramsden DA. Non-homologous end joining requires that the DNA-PK complex undergo an autophosphorylation-dependent rearrangement at DNA ends. J Biol Chem 2004; 279:39408-39413.

40 Meek K, Douglas P, Cui X, Ding Q, Lees-Miller SP. Trans auto- phosphorylation at DNA-PK's two major autophosphorylation site clusters facilitates end processing but not end joining. Mol Cell Biol 2007; 27:3881-3890.

41 Chen BP, Uematsu N, Kobayashi J, et al. Ataxia telangiectasia mutated (ATM) is essential for DNA-PK $\mathrm{CS}_{\mathrm{CS}}$ phosphorylations at the Thr-2609 cluster upon DNA double strand break. J Biol Chem 2007; 282:6582-6587.

42 Andegeko Y, Moyal L, Mittelman L, Tsarfaty I, Shiloh Y, Rotman G. Nuclear retention of ATM at sites of DNA double strand breaks. J Biol Chem 2001; 276:38224-38230.

43 Mahajan KN, Gangi-Peterson L, Sorscher DH, et al. Association of terminal deoxynucleotidyl transferase with Ku. Proc Natl Acad Sci USA 1999; 96:13926-13931.

44 Mickelsen S, Snyder C, Trujillo K, Bogue M, Roth DB, Meek K. Modulation of terminal deoxynucleotidyltransferase activity by the DNA-dependent protein kinase. J Immunol 1999; 163:834843.

45 Mahajan KN, Nick McElhinny SA, Mitchell BS, Ramsden DA. Association of DNA polymerase $\mathrm{mu}$ ( $\mathrm{pol} \mathrm{mu}$ ) with $\mathrm{Ku}$ and ligase IV: role for pol mu in end-joining double-strand break repair. Mol Cell Biol 2002; 22:5194-5202.

46 Lee JW, Blanco L, Zhou T, et al. Implication of DNA polymerase lambda in alignment-based gap filling for nonhomologous DNA end joining in human nuclear extracts. $J$ Biol Chem 2004; 279:805-811.

47 Dahm K. Functions and regulation of human artemis in double strand break repair. J Cell Biochem 2007; 100:1346-1351.

48 Niewolik D, Pannicke U, Lu H, et al. DNA-PK ${ }_{\mathrm{CS}}$ dependence of Artemis endonucleolytic activity, differences between hairpins and 5' or 3' overhangs. J Biol Chem 2006; 281:33900-33909.

49 Goodarzi AA, Yu Y, Riballo E, et al. DNA-PK autophosphorylation facilitates Artemis endonuclease activity. EMBO J 2006; 25:3880-3889.

50 Chappell C, Hanakahi LA, Karimi-Busheri F, Weinfeld M, West SC. Involvement of human polynucleotide kinase in doublestrand break repair by non-homologous end joining. Embo $J$ 2002; 21:2827-2832.

51 Valerie K, Povirk LF. Regulation and mechanisms of mammalian double-strand break repair. Oncogene 2003; 22:5792-5812.

52 Povirk LF, Zhou T, Zhou R, Cowan MJ, Yannone SM. Processing of 3'-phosphoglycolate-terminated DNA double strand breaks by Artemis nuclease. J Biol Chem 2007; 282:3547-3558.

53 Tomkinson AE, Mackey ZB. Structure and function of mammalian DNA ligases. Mutat Res 1998; 407:1-9.

54 Tomkinson AE, Vijayakumar S, Pascal JM, Ellenberger T. DNA ligases: structure, reaction mechanism, and function. Chem Rev 2006; 106:687-699.

55 Zhang X, Morera S, Bates PA, et al. Structure of an XRCC1 BRCT domain: a new protein-protein interaction module. $E M B O$ $J$ 1998; 17:6404-6411.

56 Critchlow SE, Bowater RP, Jackson SP. Mammalian DNA double-strand break repair protein XRCC4 interacts with DNA ligase IV. Curr Biol 1997; 7:588-598.

57 Grawunder U, Zimmer D, Leiber MR. DNA ligase IV binds to XRCC4 via a motif located between rather than within its BRCT domains. Curr Biol 1998; 8:873-876.

58 Sibanda BL, Critchlow SE, Begun J, et al. Crystal structure of an Xrcc4-DNA ligase IV complex. Nat Struct Biol 2001; 8:10151019. 
59 Junop MS, Modesti M, Guarne A, Ghirlando R, Gellert M, Yang W. Crystal structure of the Xrcc4 DNA repair protein and implications for end joining. EMBO J 2000; 19:5962-5970.

60 Modesti M, Junop MS, Ghirlando R, et al. Tetramerization and DNA ligase IV interaction of the DNA double-strand break repair protein XRCC4 are mutually exclusive. J Mol Biol 2003; 334:215-228.

61 Nick McElhinny SA, Snowden CM, McCarville J, Ramsden DA. $\mathrm{Ku}$ recruits the XRCC4-ligase IV complex to DNA ends. Mol Cell Biol 2000; 20:2996-3003.

62 Lee KJ, Huang J, Takeda Y, Dynan WS. DNA ligase IV and XRCC4 form a stable mixed tetramer that functions synergistically with other repair factors in a cell-free end-joining system. J Biol Chem 2000; 275:34787-34796.

63 Hsu HL, Yannone SM, Chen DJ. Defining interactions between DNA-PK and ligase IV/XRCC4. DNA Repair (Amst) 2002; 1:225-235.

64 Costantini S, Woodbine L, Andreoli L, Jeggo PA, Vindigni A. Interaction of the Ku heterodimer with the DNA ligase IV/Xrcc4 complex and its regulation by DNA-PK. DNA Repair (Amst) 2007; 6:712-722.

$65 \mathrm{Gu}$ J, Lu H, Tippin B, Shimazaki N, Goodman MF, Lieber MR. XRCC4:DNA ligase IV can ligate incompatible DNA ends and can ligate across gaps. EMBO J 2007; 26:1010-1023.

66 Tsai CJ, Kim SA, Chu G. Cernunnos/XLF promotes the ligation of mismatched and noncohesive DNA ends. Proc Natl Acad Sci
USA 2007; 104:7851-7856.

67 Nick McElhinny SA, Havener JM, Garcia-Diaz M, et al. A gradient of template dependence defines distinct biological roles for family X polymerases in nonhomologous end joining. Mol Cell $2005 ; 19: 357-366$.

68 Budman J, Kim SA, Chu G. Processing of DNA for nonhomologous end-joining is controlled by kinase activity and XRCC4/ligase IV. J Biol Chem 2007; 282:11950-11959.

69 Ma Y, Lu H, Tippin B, et al. A biochemically defined system for mammalian nonhomologous DNA end joining. Mol Cell 2004; 16:701-713.

70 Buck D, Malivert L, de Chasseval R, et al. Cernunnos, a novel nonhomologous end-joining factor, is mutated in human immunodeficiency with microcephaly. Cell 2006; 124:287-299.

71 Ahnesorg P, Smith P, Jackson SP. XLF interacts with the XRCC4DNA ligase IV complex to promote DNA nonhomologous endjoining. Cell 2006; 124:301-313.

72 Dai Y, Kysela B, Hanakahi LA, et al. Nonhomologous end joining and $\mathrm{V}(\mathrm{D}) \mathrm{J}$ recombination require an additional factor. Proc Natl Acad Sci USA 2003; 100:2462-2467.

73 Sekiguchi JM, Ferguson DO. DNA double-strand break repair: a relentless hunt uncovers new prey. Cell 2006; 124:260-262.

$74 \mathrm{Gu}$ J, Lu H, Tsai AG, Schwarz K, Lieber MR. Single-stranded DNA ligation and XLF-stimulated incompatible DNA end ligation by the XRCC4-DNA ligase IV complex: influence of terminal DNA sequence. Nucl Acids Res 2007; 35:5755-5762. 